The likeliest explanation for these fatty lesions is that they are produced by pancreatic enzymes which have entered the circulation either directly or via lymphatics. The latter is thought to be the more important route. Abdominal peritoneal lymphatic drainage and transdiaphragmatic lymphatic absorption of abdominal fluid are probably prime factors in the ingress of pancreatic enzymes to the thoracic duct and hence into general circulation (Scarpelli, 1956; Perry, 1947). Circulatory trypsin may break down vessel wall integrity and allow lipase to hydrolyse neutral fat in fat cells to glycerol and fatty acid. It has also been suggested (Hodson-Walker and Woods, 1970) that the lesions are secondary to vascular spasm or necrosis, which leads to local areas of fat necrosis. The primary insult on the vessel being from pancreatic enzymes or due to intravascular thrombosis sometimes seen in acute pancreatitis.

A further but unlikely factor is that the lesions are caused by emboli of necrotic pancreatic tissue (Blauvelt, 1946).

Peripheral fat necrosis has been described in acute pancreatitis and as a marker of pancreatic neoplasm. This case and the others described should serve as a reminder that pancreatic disease may present with bizarre and obscure symptoms and signs.

\section{Acknowledgments}

We would like to thank Dr M. J. Riddell and Mr G. Smillie for permission to publish and Dr A. Glen for invaluable help with biochemical data.

\section{References}

Blauvelt, H. (1946) Case of acute pancreatitis with subcutaneous fat necrosis. British Journal of Surgery, 34, 207.

ChIari, H. (1883) Quoted in Mullin, G.T. and others (1968). Annals of Internal Medicine, 68, 75.

Hodson-Walker, N.J. \& Woods, J.M. (1970) Acute pancreatitis with peripheral fat necrosis. Canadian Medical Association Journal, 103, 382.

ImmelmaN, E.J., BANKS, S., KRIGe, H. \& MARKS, I.M. (1964) Roentgenologic and clinical features of intramedullary fat necrosis in bones in acute and chronic pancreatitis. American Journal of Medicine, 36, 96.

Kushner, S.D. \& Szanto, P.B. (1958) Fulminant polyarthritis, fever, and cutaneous nodules in alcoholic patients. Journal of the American Medical Association, 167, 1625.

LUCAS, P.F. \& OWEN, T.K. (1962) Subcutaneous fat necrosis, 'polyarthritis' and pancreatic disease. Gut, 3, 146.

Mullin, G.T., Caperton, M.E., Crespin, S.R. \& Williams, R.C. (1968) Arthritis and skin lesions resembling erythema nodosum in pancreatic disease. Annals of Internal Medicine, 68, 75.

Perry, T.T. (1947) Role of lymphatic vessels in transmission of lipase in disseminated pancreatic fat necrosis. Archives of Pathology, 43, 456.

Roberts, J.M., BAggenstoss, A.H. \& Comfort, M.W. (1950) Acute pancreatic necrosis. American Journal of Clinical Pathology, 20, 742.

SCARPELLI, D.G. (1956) Fat necrosis of bone marrow in acute pancreatitis. American Journal of Pathology, 32, 1077.

Swerdlow, A.B., Berman, M.E., Gibbel, M.I. \& Valaitis, J. (1960) Subcutaneous fat necrosis associated with acute pancreatitis. Journal of American Medical Association, 173, 765.

VOGEL, S.F. (1951) Cerebral demyelination and focal visceral lesions in a case of acute haemorrhagic pancreatitis. Archives of Pathology, 52, 355.

\title{
Periodic migrainous neuralgia associated with an arteriovenous malformation
}

\author{
A. L. ThOMAS \\ M.B., M.R.C.P. \\ Southmead Hospital, Bristol BS10 5NB
}

\begin{abstract}
Summary
A patient with periodic migrainous neuralgia is reported. An arteriovenous malformation was found on the affected side. This association has not previously been recorded.

\section{Introduction}

In 1926 Wilfred Harris wrote of a type of recurrent facial pain and headache which he called periodic migrainous neuralgia. The syndrome was described

Present address: Medical Unit, Welsh National School of Medicine, Royal Infirmary, Cardiff CF2 1SZ.
\end{abstract}

in greater detail by Symonds (1956). Paroxysms of headache occur in bouts lasting several weeks with long intervals of freedom. There is at least one paroxysm in each $24 \mathrm{hr}$ period. The pain is agonizing and is felt mainly in the supra-orbital region, in and behind the eye, and it is strictly unilateral. The patient is woken from his sleep in the early hours of the morning and cannot lie still. It rarely lasts longer than $2 \mathrm{hr}$ and there is complete relief from pain between the paroxysms. The interval between bouts is rarely less than 6 months and may be several years. Balla and Walton (1964) documented twenty-eight 
cases and found it most common in males, their first symptoms appeared between the ages of 20 and 40 years. He listed many of the associated features of the syndrome including watering of the affected eye, blurred vision, occasional nausea, tender swollen face, and ptosis. No cause for the pain is discovered (Symonds, 1956).

A case is presented in which an arteriovenous malformation was found on the affected side. This association has not previously been described.

\section{Case history}

P.W., a 39-year-old male driving instructor, presented in 1970 with a 3-week episode of recurrent attacks of pain above and behind the right eye. These occurred each $24 \mathrm{hr}$ at 3.00 a.m. and lasted up to $2 \mathrm{hr}$. They were severe enough to wake him and he paced the bedroom floor. He had not had migraine previously and there was no relevant family history. A diagnosis of periodic migrainous neuralgia was made and he was treated with ergotamine tartrate. His symptoms settled.

In June 1973 there was a recurrence of his symptoms, but now his headaches began in late evening and lasted all night. The pain was sharp and throbbing. He noticed that his right eye watered, his vision was blurred and that he had a feeling of swelling above his right ear.
General examination showed him to be in good health. There was slight right ptosis but no change in pupil size. A localized systolic bruit was heard above and behind the right ear, where there was a palpable thrill. An arteriovenous malformation was suspected and he was admitted for arteriography.

Right carotid angiogram (Fig. 1) showed considerable enlargement of the superficial temporal artery and there was an arteriovenous malformation in the soft tissue of the scalp above the ear. There was rapid venous drainage to the external jugular vein with no abnormality in the internal carotid system.

A neurosurgical opinion was taken and it was felt that operation should not be performed since he was then symptom-free and there was no danger to his life. He has remained free of pain.

\section{Discussion}

Since Harris's initial description, various authors have described the syndrome by a variety of termserythromelagia of the head (Horton, Maclean and Craig, 1939); histamine cephalgia (Horton, 1941); greater superficial petrosal neuralgia (Gardner, Stowell and Dutlinger, 1947); cluster headaches (Kunkle et al., 1952).

This has led to confusion in diagnosis but in recent times the syndrome has become better recognized (Balla and Walton, 1964). Apart from the

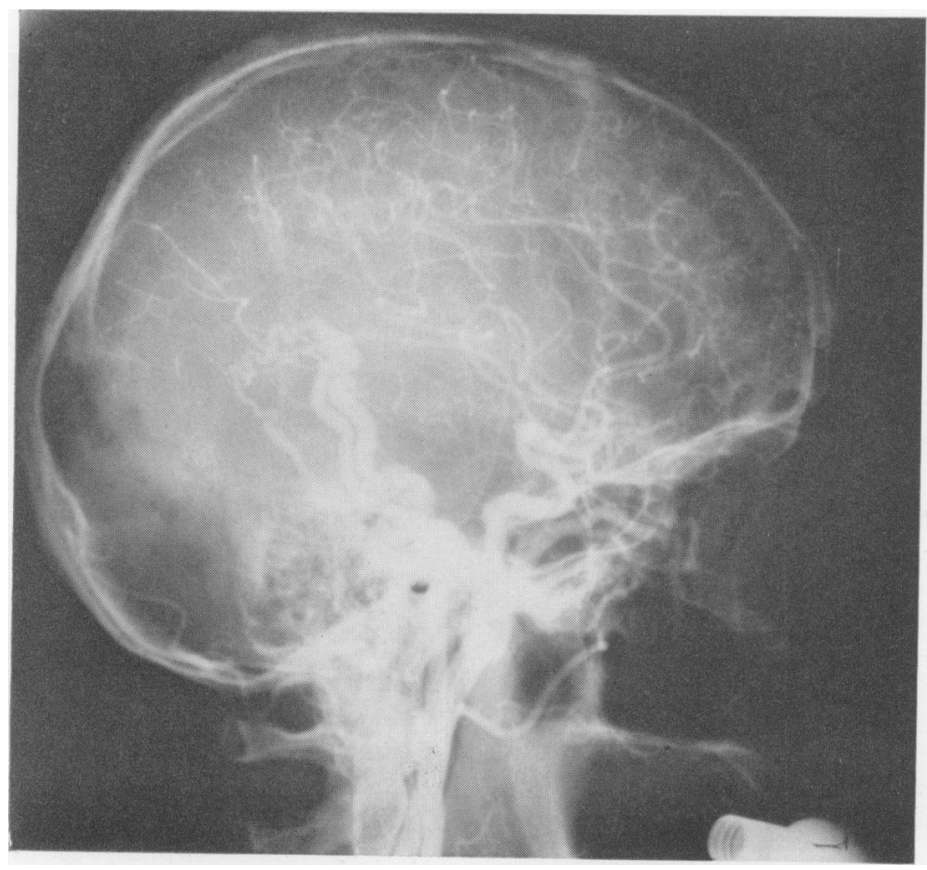

FIG. 1. 
unusual length of headache in his second bout, this case is typical. It demonstrates well the importance of listening for bruits in the head when examining a patient with headache.

The aetiology of migraine is uncertain and the literature on the subject is large and complex. It is thought that the headache is due mainly to stretching, by dilatation, of branches of the external carotid artery and possibly to a lesser extent of the internal carotid artery (Brain, 1969). The findings of vasodilator peptides as well as histamine and acetylcholine in painful regions during migraine headache points to these substances being involved (Wolff, 1972).

There is a division of opinion whether periodic migrainous neuralgia is a migraine variant or a separate entity (Bickerstaff, 1959; Balla and Walton, 1964). Broche et al. (1970) studied the cerebral and ocular circulation in several patients with the syndrome and their findings suggested that vasodilatation was present in the pulsatile intravascular bed during the pain attack being particularly pronounced on the headache side. It is probable that the two conditions share similar mechanisms of vasodilatation.

Carotid angiography was performed by Ekbom and Greitz (1970) in patients with periodic migrainous neuralgia. Four out of eighteen had generalized dilatation of the cerebral arteries and the remainder were normal.

The significance of the arteriovenous malformation in this case is a matter for conjecture. Even if the headache returned and the malformation was removed it would be difficult to judge whether operation had been successful since spontaneous remission can occur after several years (Bickerstaff, 1959).

It is of considerable interest that Heyck (1969) has tried to relate the signs and symptoms of migraine to the opening of arteriovenous shunts. He suggests the vascular changes caused in the regional circulation, together with tissue hypoxia and acidosis which lower the pain threshold, can be the cause of the migraine pain. No histological evidence of these arteriovenous vessels or their demonstration during an attack has, however, been accomplished.

The importance of examining for bruits is emphasized. This may lead to the finding of further vascular abnormalities in this form of neuralgia.

\section{Acknowledgment}

I should like to thank Dr I. S. Bailey for his helpful criticism and permission to publish this report.

\section{References}

Balla, J.I. \& Walton, J.N. (1964) Periodic migrainous neuralgia. British Medical Journal, i, 219.

BiCKerstafF, E.R. (1959) The periodic migrainous neuralgia of Wilfred Harris. Lancet, i, 1069.

BraIN W. R. (1969) Diseases of the Nervous System, 7th edition, p. 271. Oxford University Press, London.

Broche, A., Horven, I., Nornes, H., SJaAstad, O. \& Tonjum, A. (1970) Studies of cerebral and ocular circulation in the patient with cluster headache. Headache, 10, 1.

EквOM, K. \& GreITZ, T. (1970) Carotid angiography in cluster headache. Acta radiologica (Diagnosis), 10, 177.

Gardener, W.J., Stowell, A. \& Dutlinger, R. (1947) Resection of the greater superficial petrosal nerve in the treatment of unilateral headache. Journal of Neurosurgery, 4, 97.

Harris, W. (1926) Neuritis and Neuralgia, p. 418. Oxford University Press, London.

Heyck, H. (1969) Pathogenesis of migraine. In: Research and Clinical Studies in Headache, Vol. 2, p. 1. Karger, Basel.

HoRToN, B.T. (1941) The use of histamine in the treatment of specific types of headaches. Journal of American Medical Association, 116, 377.

Horton, B.T., Maclean, A.R. \& Craig, W. McK. (1939) A new syndrome of vascular headache. Proceedings of Mayo Clinic, 14, 257.

Kunkle, E.C., Pfeiffer, J.B. Jr, Wilhoit, W.M. \& HaMRICK, L.W. JR (1952) Recurrent brief headache in 'cluster' pattern. Transactions of the American Neurological Association, 77, 240.

Symonds, C. (1956) A particular variety of headache. Brain, 79, 217.

WolfF, H.G. (1972) Headache and Other Head Pain, 3rd edition, p. 351. Oxford University Press, New York. 